\title{
Socio-economic impact of Jatrophabased biofuel promotion on rural livelihoods in northern Tanzania
}

\section{Moses Olotu ( $\nabla$ m2olotu@gmail.com )}

Research

Keywords: Biofuels, food security, Jatropha, livelihoods, Arumeru, Siha, Tanzania

Posted Date: May 6th, 2020

DOI: https://doi.org/10.21203/rs.3.rs-25918/v1

License: (c) (1) This work is licensed under a Creative Commons Attribution 4.0 International License. Read Full License 


\section{Abstract}

Background In recent years, there have been global concerns regarding the continuous use of nonrenewable fossil fuels as the major source of energy. The utilization of non-renewable fossil fuels has negative effects on global warming and climate change. So far, efforts to curb the situations have tended to focus on promoting alternative renewable energy sources such as the use of biofuels to cut down emissions of green house gases. However, the production of biofuel crops has become an issue of concern in many developing countries. This is because the expansion of land for biofuel crops cultivation is directly linked to food security and the livelihoods of rural communities. The present study, therefore, aimed to evaluate the contribution of non-food biofuel crops (Jatropha curcas) to the improvement of rural household livelihoods and its impacts on food security. A survey was conducted in 84 households in Arumeru and Siha Districts in the northern Tanzania.

Results The results revealed that the introduction of Jatropha as a cash crop had no significant impact on the rural livelihoods since the five capitals of the framework have not optimally been utilised despite their presence. It was further revealed that Jatropha cultivation has not affected food security. This is contrary to fears that biofuels could generally have a negative impact on food security especially in developing countries. The crop had not been regarded as a cash crop or a biofuel; thus, a very little percentage of land owned by the respondents had been allocated for its cultivation. The importance of Jatropha in the study area has yet to be recognised and given the special attention it requires.

Conclusions It can be concluded that, the current situation does not indicate any significant impact of Jatropha cultivation on food security. However, it has little contribution to livelihood improvement of the smallholder farmers. Therefore, research on the improvement of Jatropha productivity under optimum conditions and pricing should be further undertaken in different areas of the country.

\section{Introduction}

Energy from biomass continues to be a focus of worldwide research due to negative effects of fossil fuels (Sulle and Nelson 2009). One potentially promising alternative source of energy is biofuels because they are derived from biomass and have a closed carbon cycle that do not contribute to emit greenhouse gases. The biomass required to produce biofuels could be either derived from oil producing crops like Jatropha and oil palm (Bassey 2009; Sulle and Nelson 2009). While several countries have considerably increased their production for domestic demand, the international biofuels market is clearly set to grow. For example, European biofuels quotas of attaining a 10\% biofuels share by 2020 can only be met by imports. So far, biofuel crops are widely promoted in Africa as they relatively grow faster in the tropics; as such, they help to meet significant requirements for large-scale production (Gasparatos et al. 2015). Notwithstanding, the biofuels exploration data suggests that several foreign private companies are interested to work in Africa biofuel projects due to its less costs (i.e. cheap labour and land acquisition) of production (Cotula et al 2008; Mkoma and Mabiki 2011). In Tanzania, the production of biofuel has the potential to provide a substitute for costly oil imports estimated to range between US\$1.3 and 1.6 billion 
per annum (Ewing and Msangi 2009). High levels of macro-economic growth have resulted in increasing levels of energy consumption, and rising prices of existing energy sources. Evidence suggests that biofuel expansion is technically feasible in Tanzania (Sulle and Nelson 2009; Mkoma and Mabiki 2011). Moreover, biofuels create employment and income opportunities and new rural industries.

Among the biofuel crops, Jatropha curcas (Linnaeus) is currently an outstanding crop for the production of biodiesel due to its ability to grow in marginal land and drought resistant (Sulle and Nelson 2009; Luna et al. 2010). The genus Jatropha comprise about 170 known species of this wild plant (Augustus et al. 2002; Jongschaap et al. 2007). It is a perennial bush tree that can reach height up to $8 \mathrm{~m}$ with lifespan of 50 years (Augustus et al. 2002). Initially, the crop was used largely to prevent and/or control erosion, reclaim land and served as a live fence to protect agricultural fields from farm animals (Luna et al. 2010; Islam et al. 2011). The status of Jatropha has, however, since changed and cultivated extensively as an alternative commercial crop. Governments and private companies are interested in its products, especially seeds, from which oil are extracted and used as feedstocks for biodiesel production (Luna et al. 2010; Islam et al. 2011). In Africa, the crop can either grow naturally or cultivated; but there is little reliable scientific data for its environmental assessment and management. So far, the main agroenvironmental impact studies in East African countries are qualitative. This includes Achten et al. (2008) in Kenya and van Eijck and Romijn (2008) in Tanzania. Although, biofuels industry in Tanzania is still at infancy stage as most projects started in 2006, the government is in the forefront in promoting the production of biofuels (Ewing and Msangi 2009). Its promotion aimed at reducing emissions of greenhouse gases in the light of climate change, diversifying energy sources and creating markets for agricultural energy crops which will eventually improve rural development (Ewing and Msangi, 2009). In 2011 , they grew the crop at estimated areas covering 17,000 ha, which is equivalent to $14.4 \%$ of the total areas practising Jatropha cultivation in Africa (Mkoma and Mabiki 2011).

Despite the promising potential of biofuel crops, its production has raised a major concern for food security and its impacts on the livelihoods of rural communities in Tanzania. As a result, cultivation of non-food feedstocks such as Jatropha was proposed as an alternative biofuel crop in the country (Cotula et al. 2009; Sulle and Nelson 2009). The high dependency on subsistence agriculture requires a very keen and careful allocation of land to other uses. In Tanzania, there is no policy on biofuels that has given guidance to biofuel actors. Acreages of good arable land and natural forests are being allocated for biofuels production (Sulle and Nelson 2009). This might produce food scarcity and providing grounds for displacement of poorer people from land. Most times, land perceived to be 'idle', "underutilized", and "marginal" or "abandoned" by government and investors is vital for the livelihoods of indigenous people. Several questions arise, such as are there enormous areas of unused land? Could investment in large biofuel plantations have repressive displacement on locals who do not have access to pertinent information?

The lack of proper knowledge of Jatropha on predictions of its productivity, its compatibility with other agricultural crops and its contribution to the rural livelihoods is a major constraint for its extended use. There is little knowledge on its potential benefits to livelihoods of poor rural communities in Tanzania. 
This makes it difficult to predict its livelihoods contribution to the smallholder farmers. Reliable predictions of the productivity are necessary to make reasonable decisions on investment (Jongschaap et al. 2007). The present study, therefore, carried out to evaluate the contribution of Jatropha to smallholder farmers' livelihoods and its impacts on food security as well as social acceptability in northern Tanzania.

\section{Materials And Methods \\ 2.1 Study area}

The study was conducted in two neighbouring districts of Arumeru in Arusha region and Siha district (formally part of Hai district) in Kilimanjaro region. Arumeru and Siha are located between latitudes and longitudes $S 03^{\circ} 17^{\prime}, \mathrm{E} 35^{\circ} 47^{\prime}$ and $\mathrm{S} 03^{\circ} 10^{\prime}, \mathrm{E} 37^{\circ} 10^{\prime}$, respectively (Fig. 1). The two districts are well known as major Jatropha growing areas in the northern Tanzania. These areas receive a bimodal rainfall regime and experience a short rainy season from November to December and the long and heavy rainy season from March to June. The amount of rainfall ranges from $1000 \mathrm{~mm}$ to $2000 \mathrm{~mm}$, and the mean annual temperature is $24^{\circ} \mathrm{C}$ (JPTL office record 2009). These areas have neo-gene soils characterised by typical alkaline volcanic rock material such as olivine basalt, alkali basalt and others.

\subsection{Research design}

The study used explorative research design whereby a sustainable livelihood approach was employed as a logical framework. The method allows data to be collected from different respondents at a single point in time (Zheng 2015). It also helps to collect data from a pool of respondents with varied characteristics and demographics (Jarvista 2003). The study also deployed both simple probability and non-probability sampling procedures. In the former, each individual had an equal chance of being included in the sample and, therefore, was selected by chance. In the latter, purposive sampling was used to select household engaged in Jatropha cultivation (Kothari 2012).

Three villages were purposively selected as the units from which inferences can be made to have a generalized view of Jatropha cultivation in the region. According to Yin (1994), this kind of study focuses on contemporary phenomenon with real life. Such study has the following characteristics: (i) deep and holistic knowledge about the cases involved, (ii) focus on understanding and interpreting the case from an inside perspective, (iii) observations are done in a natural context, and (iv) utilization of multiple labour intensive methods of data generation.

\subsection{Sampling procedures}

Purposive sampling was employed to select three villages viz., Sihakati, Naibili and Leguruki, in Sihakati, Sabuko Leguruki wards, respectively. The selected villages had a homogenous environment in terms of ethnicity and production system (i.e. subsistence agriculture). Also, because Jatropha is cultivated as a newly introduced cash crop; thus, not every village in the two districts is taking part in its cultivation. Twenty eight (28) households from each village were selected as the sample unit, making a grand total of 
84 households for the entire study. Jatropha Products Tanzania Limited (JPTL) agency random sampling techniques were employed for the selection of households to avoid bias.

\subsubsection{Questionnaire survey}

A questionnaire is a data generation technique in which respondents provide written responses to questions or statements that require factual information (Best and Khan 2006). Using a structured questionnaire as a tool comprised open and closed-ended questions. The open-ended questions gave the respondents an opportunity to express their views and to increase the level of interaction between the two stakeholders (the researcher and respondents). Structured questionnaires were administered to respondents comprising the same questions in the same order. Household survey is designed to provide information of the whole community and represents a complete geographical area (Polit 2001). Data collected include the importance of Jatropha cultivation, its socio-economic contribution and its impacts on food security.

\subsubsection{Key informants and household interviews}

Key informants were relevant government ministries such as the Ministry of Energy and Mineral (MEM) and the Ministry of Agriculture Food and Co-operatives (MAFC). It also involved private sectors like Kampuni ya Kusambaza Teknolojia (KaKuTe) and Jatropha Products Tanzania Limited (JPTL), NGOs and local government bodies with the responsibility of foreseeing a smooth introduction of biofuels as cash crops. A native assistant researcher from JPTL accompanied a visit to a household in the selected villages, who also served as a translator in case the respondent could not speak Swahili. The researcher assistant had served as the extension officer in-charge and involved to supply Jatropha seedlings to members of the groups.

\subsubsection{Asset mapping}

This method was employed to portray the economic status of households in question, which was done through physical field observation. Parameters observed were housing structures, roofing materials, sources of water for domestic purposes and other physical assets. The data was then compared with questionnaire results for validation. Direct observation is a powerful method for gaining insights into the situation (Kothari 2012). A checklist and photographs were tools used to facilitate data collection in this method.

\subsubsection{Document reviews}

Document reviews were used to collect secondary data (Kothari 2012). First, existing literature and media reports were reviewed; particular emphasis was placed on reviewing recent studies by other organizations and actors involved with Jatropha, for example NGOs which examine the social and environmental dimensions of biofuel development trends such as the WWF (Kamanga 2008).

\subsection{Data Analysis}


Descriptive statistics were used to summarise and present data into frequency tables and charts. Socioeconomic characteristics of respondents were also interpreted and presented as distributions, percentages and mean scores. The data was analysed in line with the objectives using Statistical Package for Social Sciences version 20 (SPSS 20) and subjected to content analysis. Content analysis is a "research method for the subjective interpretation of content of text data through a systematic classification process of coding and identifying themes or patterns" (Hsieh and Shannon 2005).

\subsection{Limitation of the Study}

Some respondents were reluctant to be interviewed on the pretext that they could not see the benefits of them being interviewed and the exercise was considered as a waste of their time. However, the purpose of the study was adequately clarified including assurance of getting the results and recommendations to improve their general understanding and participation in research activities. There was also an issue of language barrier when some respondents could not speak in Swahili as a result local interpreter was also engaged during the household interviews. Furthermore, the study was qualitative in nature and, hence, the findings can be transferred to other areas only if they have characteristics similar to those of the sampled villages (one ethnicity group and production system).

\section{Results}

\subsection{Sex and land ownership of respondents}

The results revealed that most respondents were males (68\%) compared to females (32\%) in Sihakati. A similar trend was also observed in Naibili and Leguruki, where males and females varied from $61-39 \%$ in each village. The majority of male respondents (82\%) owned land, followed by females (18\%) in Sihakati. The proportional of respondents in terms of their ownership to land were high in males (71\%) compared to those of females (25\%) and $4 \%$ by both sexes in Leguruki. It further revealed that majority of male respondents (57\%) owned land, followed by females (39\%) and at least $4 \%$ by both sexes in Naibili.

\subsection{The level of education of the respondents}

The results revealed that most respondents had a primary education, followed by ordinary education, and least had college/university education. Between 4 and $7 \%$ of the respondents did not attend any formal education (Fig. 2). There was also a positive correlation between education level and size of land allocated for Jatropha cultivation. For example, regression coefficient varied between villages as follows: $\left(r=0.258\right.$ and $\left.r^{2}=0.067\right)$ in Sihakati, $\left(r=0.085\right.$ and $\left.r^{2}=0.007\right)$ in Leguruki and $\left(r=0.064\right.$ and $\left.r^{2}=0.004\right)$ in Naibili.

\subsection{Age group distribution}

The highest participation of households in Jatropha cultivation was recorded at the age class of 3847 years old, followed by the age class of $48-57$ years old in both villages. The lowest participation of 
households in Jatropha cultivation was recoded at the age class of 18-27 years old in Naibili and Sihakati (Fig. 3). Participation statuses of other age groups in Jatropha cultivation are shown in Fig. 3.

On the other hand, there was a positive correlation between age (up to an optimum age) and participation in Jatropha cultivation. The participation in this case was measured by size of land allocated for Jatropha cultivation. There was a positive correlation between optimal age and effective participation in Jatropha cultivation (Fig. 4). The regression coefficient varied between villages, the strongest positive correlation was recoded in Naibili $\left(r=0.558\right.$ and $\left.r^{2}=0.312\right)$, followed by Leguruki $\left(r=0.313\right.$ and $\left.r^{2}=0.028\right)$ and least regression coefficient was recorded in Sihakati $\left(r=0.166\right.$ and $\left.r^{2}=0.022\right)$.

\subsection{The importance attached to Jatropha}

The introduction of Jatropha as a new cash crop is looked upon with very keen interest given the scarcity and importance of land for its cultivation. The results revealed that more than $50 \%$ of the respondents allocated about 1-2 ha of their land for its cultivation (Fig. 5). Moreover, Labour input was used as a good indicator of the importance the smallholder farmers attached to it. The results revealed that more than $95 \%$ of the respondents utilised between 1 and 2 hours per week in Jatropha cultivation. It was also shown that more than $40 \%$ of the respondents utilised between 43 and 58 hours per week in other farming activities.

\subsection{The impact of Jatropha on food security and livelihood}

The results revealed that the majority of respondents (86\%) points out that food security was not affected by Jatropha cultivation in both villages. Furthermore, most respondents $(69 \%)$ were not willing to associate their household livelihood standards and effective engagement in Jatropha cultivation. However, few respondents associated their participation in cultivation to the numbers of children enrolled to schools (14\%), nutritional status and dietary (9\%), employment opportunities (7\%) and housing structure $(1 \%)$.

\section{Discussions}

\subsection{The importance of education to Jatropha cultivation}

The success of Jatropha transformation as a cash and environmental mitigating crop depends on education levels, skills and technical know-how of the participants at a grass root level. The results revealed that households engaged in Jatropha cultivation follow a patrimonial way of life whereby the man acted as head of the household and in most cases owned land. There was a significant correlation between education level and effective participation of smallholder farmers in Jatropha cultivation. This implies that householder farmers with primary and ordinary education were more productive and engaged effectively in farming activities including Jatropha cultivation. This result concurs with studies done by Carnoy (1992) and Oduro-Ofori at al. (2014) who observed a great correlation between education 
and participation in agricultural productivity. However, the present study could not support the assumption that the higher level of education (college/university) tends to increase chances of participating in new innovations. This is because effective participation of locals in Jatropha cultivation requires some level of education within communities. It was observed that appropriate non-formal skills training for adults and school dropouts enable rural people to diversify their skills to improve livelihood and resiliency during times of stress (FAO 2007; Scoones 2009).

\subsection{The association between age, land and cultivation of Jatropha}

Age is one of the key components of social capital in participation of local communities in developmental activities. It was therefore used as an important indicator to substantiate participation of local communities in cultivation of Jatropha. It was found out that youths had the lowest involvement in cultivation of Jatropha. This is probably because the crop was considered an edge plant with no economic benefits. Thus, the rural youth tend to be relatively mobile and migrated to urban areas. The effect of rural-urban migration on agricultural production has been reported to jeopardise the coping strategies of the rural poor worldwide (Deshingkar 2004; Ampomah 2013; Cho et al. 2019). Studies elsewhere have revealed that the capacity of households or individuals to participate in rural farming activities varies significantly within and between countries (Ampomah 2013; Cho et al. 2019).

Generally, the increasing absence of young people in rural areas for agricultural activities has been attributed to farm drudgery, absence of social infrastructure, poor farming incomes and the overall low life expectancy in rural societies (Mitchell and Shepherd 2006). As a result, young people within the active working age class and with the requisite education to cope with the challenges of modernizing the means of farm production are compelled to migrate to urban areas. This kind of migration could be due to search of better economic opportunities and improved standards of living. It was observed that most of the landowners acquired their land through inheritance. Such a situation probably did not encourage the youths to take part in Jatropha cultivation. However, non-farm activities can be very important to the landless and poor people in rural areas (Ellis 2000). This study revealed that majority of respondents engaged in the cultivation of Jatropha was at the age class of 38-48. At this age class, they have established homes and families to take care of with little chances of migration; as such, they participated effectively in Jatropha cultivation. On the other hands, the younger household members frequently migrated in search for non-farm, income-earning opportunities (Smith 2000).

The poor attachment of smallholder farmers to Jatropha cultivation could be attributed to small size of land allocated to its cultivation. It was further observed that most of the Jatropha crops were cultivated in farm edges, which is regarded as marginal land. The importance and scarcity of land though not much pronounced in Tanzania, has been influenced by the population growth. There is a connection between land use and livelihoods outcomes and such outcomes could best be understood as co-produced (McCusker and Carr 2006).

\subsection{The impacts of Jatropha on food security and livelihood}


Food security has been a major concern to human from time immemorial. Food security exists when all people, at all times, have physical and economic access to sufficient, safe and nutritious food that meets their dietary needs and food preferences for an active and healthy life (Peng and Bery 2019). The production of biofuels is one of the reasons attributed to elucidate increase in prices and concern of household over food security. This study revealed that Jatropha cultivation has no effect on food security as over $86 \%$ of respondents had no food shortage. However, $14 \%$ of respondents with shortage of food could be attributed to drought conditions in the past five years. Cultivation of Jatropha had no threat to food security because it was mostly planted along boarder lines for fencing thus creating no competition to agricultural lands. Intercropping system was also practiced, which include planting Jatropha with staple food crops.

Majority of the respondents (69\%) quantified that participation in the cultivation of Jatropha had no impact on their livelihoods. While $14 \%$ of the respondents had their children enrolled in school because of Jatropha, most of these were not solely from their farms alone, but rather the children themselves were collecting seeds from Jatropha grown in the wild. Few respondents (7\%) had the chance of getting employment opportunities mainly from soap making and seed collection. Furthermore, $9 \%$ and $1 \%$ had their nutritional status improved and housing structures changed, respectively. This implies that the cultivation of Jatropha is not economically feasible to the extent of improving food security and livelihood of locals. Studies revealed that the production of Jatropha is not economically attractive and it negatively affects food security and the livelihood of rural people in Ghana (Acheampong and Campion 2014) and Botswana (Mmopelwa et al. 2017).

\section{Conclusions}

The current situation does not indicate any significant impact of Jatropha cultivation on food security; however, it has little contribution to livelihood improvement of the smallholder farmers. The crop had not been regarded as a cash crop or a biofuel; thus, a very little percentage of land owned by the respondents had been allocated for its cultivation. The importance of Jatropha in the study area has yet to be recognised and given the special attention it requires. The central government, local government and all other actors involved in the promotion of Jatropha are required to put more initiative in creating awareness and promotion of using Jatropha both as a source of income and energy in rural areas.

There is also a need, to employ new approaches and strategies to boost its productivity, especially price increase of Jatropha seeds so as to make it a competitive cash crop to coffee production. Although, currently, the cultivation of Jatropha is not threatening food security, there must be a policy to regulate the actors in terms of what is to be planted and where, how much of land is to be allocated for biofuels in general. Research on the improvement of Jatropha productivity under optimum conditions and pricing should be further undertaken in different areas of the country.

\section{Availability of data and materials}

The datasets used and/or analysed in this study are available from the corresponding author on request. 


\section{Declarations}

\section{Acknowledgements}

The authors acknowledge to all village leaders and staff working with Jatropha Production Tanzania Limited (JPTL) in Arusha who, in many ways, contributed their ideas, comments, suggestions and the data, which contributed to the completion of this study.

\section{Funding}

This study was supported by the Federal Ministry for Economic Cooperation through Development and the German Academic Exchange Service (DAAD), Germany.

\section{Author information}

John E. Rutagwaba ${ }^{1}$ and Moses I. Olotu ${ }^{2}$

\section{Affiliations}

${ }^{1}$ Tanzania Forest Services (TFS) Agency, Ministry of Natural Resources and Tourism, P.O. Box 40832, Dares-Salaam, Tanzania

${ }^{2}$ Department of Biological Sciences, Mkwawa University College of Education (MUCE), University of Dares-Salaam, P. O. Box 2513, Iringa Tanzania

\section{Contributions}

John Rutagwaba devised the main theoretical framework and performed data collection. Moses Olotu took the lead in writing the manuscript and provided significant feedback and helped shape the research, analysis and manuscript. The author(s) read and approved the final manuscript.

\section{Corresponding author.}

Moses I. Olotu* E-mail: m2olotu@gmail.com and ORCID ID: https://orcid.org/0000-0001-9129-4769

\section{References}


Acheampong E, Campion BB (2014) The Effects of Biofuel Feedstock Production on Farmers' Livelihoods in Ghana: The Case of Jatropha curcas. Sustainability 6(7): 4587-4607.

Achten WMJ, Verchot L, Franken YJ, Mathijs E, Singh VP, Aerts R, Muys B (2008) Jatropha bio-diesel production and use. Biomass and Bioenergy 32: 1063-1084.

Ampomah A (2013) The effect of rural-urban migration on agricultural production in the northern region of Ghana. Journal of Science and Applications 2(4): 193-200.

Augustus GDPS, Jayabalan M, Seiler GJ (2002) Evaluation and bio induction of energy components of Jatropha curcas. Biomass \& Bioenergy 23:161-164.

Bassey N (2008) The Agrofuels Debate in Africa: Challenges and Opportunities. Conference Proceeding on Ecological Agriculture: Mitigating Climate Change, Providing Food Security and Self-Reliance for Rural Livelihoods in Africa, held at the AU Headquarters, Addis Ababa 26-28 November 2008.

Best JW, Khan JV (2006) Research in education, New Delhi, Prentice Hall of India.

Carnoy M (1992) The Case for Investing in Basic Education. Children's Fund. U.N. New York.

Cho KM, Kyaw K, Khaing PP (2019) Effects of rural-urban migration on agricultural production in Taungdwingyi Township, Magway Region, Myanmar. In: James H (eds) Population, Development, and the Environment. Palgrave Macmillan, Singapore.

Cotula L, Vermilion S, Leonard R, Keeley J (2009) Land grab or development opportunity? Agricultural investment and international land deals in Africa, IIED/ /IFAD, London/Rome.

Ellis F (2000) Rural Livelihoods and Diversity in Developing Countries, Oxford, Oxford University Press.

Ewing M, Msangi S (2009) Biofuels production in developing countries: Assessing trade-offs in welfare and food security. Environmental Science and Policy 12: 520-528.

Food and Agriculture Organization (2007) Proceedings of the first FAO technical consultation on bioenergy and food security. 16-18 April 2007. Food and Agriculture of the United Nations, Rome, Italy.

Gasparatos A, von Maltitz GP, Johnson F X, Lee LY, Mathai M, Puppim de Oliveira JA, Willis K J (2015) Biofuels in Africa: drivers, impacts and priority policy areas. Renewable and Sustainable Energy Reviews 45: 879-901.

Hsieh H, Shannon SE (2005) Three Approaches to Qualitative Content Analysis. Qualitative Health Research 15: 1277-1288.

Islam AKM, Yaakob Z, Anuar N (2011) Jatropha: A multipurpose plant with considerable potential for the tropics. Scientific Research and Essays 6(13): 2597-2605. 
Jarvista $R$ (2003) Cross-Sectional Study: Definition, Advantages, Disadvantages and Example. Lesson Transcript. Retrieved from http://study.com/academy/lesson/cross-sectional-study-definitionadvantages-disadvantages-example.htm

Jongschaap REE, Corré WJ, Bindraban PS, Brandenburg WA (2007) Claims and facts on Jatropha curcas L. Plant Research International B.V, Wageningen, The Netherlands. http://tinyurl.com

Kamanga KC (2008) The Agrofuel Industry in Tanzania: A Critical Enquiry into Challenges and Opportunities. A research report. Hakiardhi and Oxfam Livelihoods Initiative for Tanzania (JOLIT), Dar es Salaam.

Kothari RC (2012) Research Methodology. Methods and Techniques, New age International Publishers. Second Revised Edition, India.

Luna D, Verdugo C, Luque R, Herrador JMH (2010) Jatropha curcas (L): a promising biofuel plant. current status and future prospects, In: Ponterio C, Ferra C (eds) Jatropha Curcas as a Premier Biofuel: Cost, Growing and Management, Nova Science Publishers, Inc. New York, p.1-40.

McCusker B, Carr ER (2006) The Co-production of livelihoods and land use change: Case studies from South Africa and Ghana. Geoforum 37 (5): 790-804.

Mitchell J, Shepherd A (2006) Productive Strategies for Poor Rural Households to Participate Successfully in Global Economic Processes, Technical Report published by Overseas Development Institute. Retrieved from https://www.odi.org/sites/odi.org.uk/files/odi-assets/publications-opinionfiles/1682.pdf?

Mkoma SL, Mabiki FP (2011) Theoretical and Practical Evaluation of Jatropha as Energy Source Biofuel in Tanzania, Economic Effects of Biofuel Production, Marco Aurélio dos Santos Bernardes, Intech Open, DOI: $10.5772 / 16476$.

Mmopelwa G, Kgathi DL, Kashe K, Chanda R (2017) Economic Sustainability of Jatropha Cultivation for Biodiesel Production: Lessons from Southern Africa. Journal of Fundamental Renewable Energy 7: 244. doi: 10.4172/2090- 4541.1000244

Oduro-Ofori E, Aboagye AP Acquaye NAE (2014) Effects of education on the agricultural productivity of farmers in the Offinso Municipality. International Journal of Development Research 4(9): 1951-1961.

Peng W, Berry EM (2019) The concept of food security. In: Ferranti P, Berry EM, Anderson JR (eds) Encyclopedia of Food Security and Sustainability, vol. 2.

Polit DE (2001) Essentials of Qualitative Research. $3^{\text {rd }}$ Edition. New York. Eippincott, Williams and Wilkins. Qualitative Health Research 15,9: 1277-1288. 
Scoones I (2009) Livelihoods perspectives and rural development. The Journal of Peasant Studies 36 (1): 171-196.

Smith D (2000) The Spatial Dimensions of Access to Rural Non- Farm Economy. Draft Paper Chatham, UK. Natural Resources Institute.

Sulle E, Nelson F (2009) Biofuels, land access and rural livelihoods in Tanzania, IIED, London van Eijck J, Romijn H (2008) Prospects for Jatropha biofuels in Tanzania: An analysis with Strategic Niche Management. Energy Policy 36 (1): 311-325.

Zheng M (2015) Conceptualization of Cross-Sectional Mixed Methods Studies in Health Science: A Methodological Review. International Journal of Quantitative and Qualitative Research Methods 3,2: 6687.

\section{Supplementary Files}

This is a list of supplementary files associated with this preprint. Click to download.

- RutagwabaandOlotuSupplementaryInformation.docx 